Jurnal Geocelebes Vol. 5 No. 2, Oktober 2021, 131 - 143

\title{
GEOLOGI DAN KESTABILAN LERENG DALAM PEMETAAN ZONASI LONGSOR DI DESA SEBERANG DAN SUMUR GEDANG, KECAMATAN PESISIR BUKIT, KOTA SUNGAI PENUH, JAMBI
}

\author{
Fandi Frananda*, Itang Ahmad Mahbub, Anggi Deliana Siregar \\ Teknik Geologi, Universitas Jambi, Jl. Jambi-Muara Bulian No.KM. 15, Jambi, Indonesia. \\ *Corresponding author. Email: fandifrananda08@gmail.com
}

Manuscript received: 6 July 2021; Received in revised form: 1 September 2021; Accepted: 18 September 2021

\begin{abstract}
Abstrak
Longsor terjadi diakibatkan kestabilan lereng yang terganggu maka gerakan tanah (longsoran) akan terjadi dan dapat menimbulkan kerugian besar bagi masyarakat di sekitarnya. Kota Sungai Penuh cecara fisiografis berada di tepi bagian muka Lempeng Benua Asia yang berbenturan dengan Lempeng Samudera Hindia mengakibatkan sering dilanda bencana geologi. Kecamatan Pesisir Bukit merupakan daerah rawan akan potensi gerakan tanah longsor berdasarkan peta perkiraan gerakan tanah longsor untuk periode bulan Januari hingga Februari 2018. Penelitian ini bertujuan untuk memetakan zonasi longsor daerah penelitian berdasarkan kestabilan lereng dari data lapangan dan laboratorium. Metode penelitian menggunakan metode survei dan observasi lapangan. Hasil penelitian ini menunjukan daerah penelitian dibagi menjadi zona rendah (stabil), menengah dan tinggi (labil) berdasarkan ketentuan PVMBG. Zona berpotensi rendah dapat ditemukan adanya tanah longsor, namun ditemukannya tanah longsor ini jarang, namun dapat terjadi jika adanya faktor yang memicu longsor. Zona berpotensi menengah menandakan bahwa pada daerah tersebut ditemukannya kejadian longsor cukup banyak, merupakan daerah berbukit, tutupan lahan dengan curah hujan cukup tinggi. Sedangkan zona berpotensi tinggi menandakan daerah sangat berpotensi longsor, umumnya ditemukan pada daerah lereng terjal dengan intensitas curah hujan tinggi dan bencana tanah longsor pada daerah ini akan sering terjadi.
\end{abstract}

Kata Kunci: Kestabilan Lereng; Longsor; Zonasi Longsor.

\begin{abstract}
Landslides occur due to the stability of disturbed slopes, then the movement of landslides (avalanches) will occur and can cause great losses for the surrounding communities. Sungai Penuh city Phsographically located on the edge of the face of the Asian Continental Plate that collides with the Indian Ocean Plate resulting in areas often hit by geological disasters. Bukit Pesisir District is an area prone to the potential for landslide movement based on the landslide movement forecast map for the period january to February 2018. This research aims to find out the mapping of landslide zoning in Sebrang Area and Sumur Gedang based on data in the field and in the laboratory. The results of this study showed that the research area was divided into low (stable), medium and high (labile) zones based on PVMBG provisions. In low potential zones have the possibility of landslides, but rare and can occur if there are factors that trigger landslides. The medium potential zone indicates that in the area there are quite a lot of landslide events, and the area is a hilly area and land cover with high rainfall. While the high-potential zone indicates that the area is very potential for landslides, it is generally found on steep slope areas with high rainfall intensity and landslide disasters in this area will often occur.
\end{abstract}

Keywords: Landslide; Landslide Zoning; Slope Stability. 


\section{Pendahuluan}

\section{Latar Belakang}

Longsor merupakan suatu bentuk erosi dengan proses pengangkutan atau pemindahan tanah terjadi pada suatu saat dalam volume yang besar (Natawidjaja, 2018). Longsor dapat terjadi karena ketidakstabilan lereng, lereng adalah suatu permukaan tanah yang miring dan membentuk sudut tertentu terhadap suatu bidang horizontal dan tidak terlindungi (Das et al., 1995). Ketika stabilitas lereng terganggu maka gerakan tanah (longsoran) akan terjadi dan dapat menimbulkan kerugian yang cukup besar bagi masyarakat di sekitarnya. Masalah stabilitas lereng terjadi pada permukaan tanah akibat aktivitas manusia maupun faktor alam seperti curah hujan, jenis tanah.

Kota Sungai Penuh secara topografis terletak di tengah Taman Nasional Kerinci Seblat (TNKS), wilayah ini dikelilingi oleh bukit barisan dan pegunungan. Salah satu penyebab rawan longsor pada daerah penelitian yaitu permasalahan lingkungan dan sosial yang menonjol seperti pertanian intensif, kerusakan hutan atau luasnya lahan kritis di Kota Sungai Penuh yang mencapai 180.305 ha dengan tingkat curah hujan tahunan berkisar 49,4 - 169,9 mm pertahun (Dinas Pekerjaan Umum, 2015). Berdasarkan struktur geologi daerah penelitian berupa lipatan, patahan, dan kelurusan banyak dijumpai, yang umumnya berarah Tenggara-Baratlaut. Struktur patahan memengaruhi seluruh batuan penyusun yang terbentuk di PraHolosen bahkan hingga Resen. Patahan ini memengaruhi pula terhadap endapan aluvium di bagian dataran, yang tercerminkan oleh adanya retakan/ lipatan dan kelurusan.

Penelitian ini dimaksudkan untuk mengetahui kondisi geologi daerah penelitian, tingkat kerentanan stabilitas lereng daerah penelitian berdasarkan analisis fisik tanah, penetapan zona kerentanan longsor yang dimuat dalam peta kerentanan longsor dan memberikan solusi dalam perencanaan wilayah pada daerah yang rentan terhadap longsor.

Adapun tujuan dari penelitian ini yaitu sebagai berikut:

1. Mengetahui geologi daerah penelitian dengan melihat perbedaan litologi, bentukan asal dan lahan, serta struktur yang berkembang di daerah penelitian.

2. Mengetahui pengaruh dari data jenis batuan, sifat fisik dan mekanik tanah serta data yang diperlukan lainnya seperti penggunaan lahan dan kemiringan lereng dalam terhadap bencana longsor.

3. Mengetahui nilai faktor keamanan lereng dan rekomendasi tepat sebagai dasar dalam suatu pembangunan di daerah penelitian yang rentan terhadap gerakan tanah/ longsor.

\section{Kajian Pustaka}

1. Fisiografi Daerah Penelitian

Daerah penelitian terletak di sebagian rangkaian Pegunungan Barisan dan Zona Sesar Semangko dalam hal ini Segmen Sesar Siulak (Gambar 1). Rangkaian Pegunungan Barisan tersebut dikenal sebagai Lajur Zona Magmatic Busur Barisan yang di dalamnya terdapat Zona Sesar Besar Sumatera. Zona Jajaran Barisan merupakan suatu zona perbukitan memanjang dengan arah orientasi Tenggara-Baratlaut dengan panjang \pm 1650 $\mathrm{km}$ dengan lebar $100 \mathrm{~km}$ (Bemmelen, 1949).

Zona Sesar Sumatera atau Zona Sesar Semangko adalah zona yang memiliki pola memanjang yakni pola zona ini mengikuti fisiografi dari Bukit Barisan. Zona ini merupakan geoantiklin yang memanjang dengan bentuk depresi, zona ini memanjang dimulai dari Teluk Semangko (Sumatera Selatan Lampung) hingga ke bagian Baratlaut di Kotaradja Aceh yang merupakan suatu lembah dan batas akhir dari zona ini (Bemmelen, 1949). 


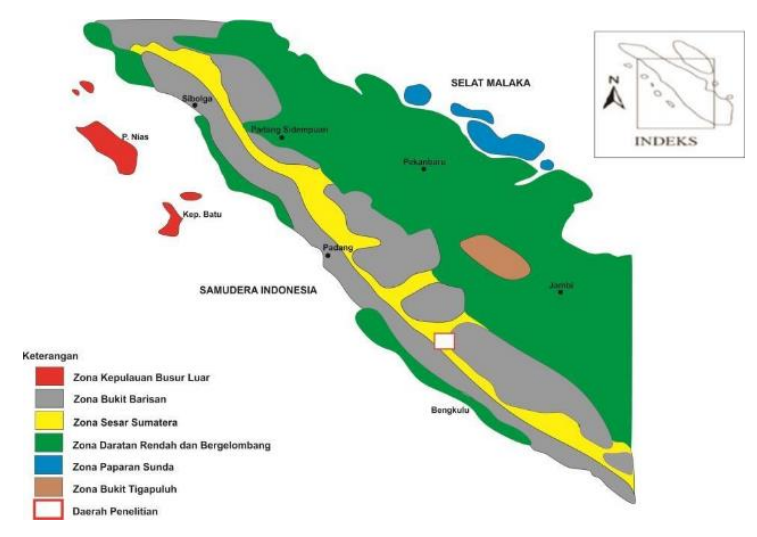

Gambar 1. Fisiografi Regional (Bemmelen, 1949).

\section{Tektonik dan Struktur Geologi}

Daerah penelitian termasuk kedalam sistem tektonik Zona Sesar Sumatera. Sesar Semangko merupakan bagian selatan dari Sistem Sesar Besar Sumatera yang merupakan akibat subduksi atau konvergensi menyerong antara Lempeng Indo-Australia dengan Lempeng Eurasia. Segmen Sesar Semangko membentang sepanjang lebih dari $80 \mathrm{~km}$ dari Selat Sunda sampai dengan daerah Danau Ranau di utara. Sesar Sumatera merupakan sesar strike slip berarah dekstral yang terdiri dari 19 segmen utama sepanjang tulang punggung Sumatera (Sieh and Natawidjaja, 2000). Sesar Siulak merupakan sesar yang berada pada jalur vulkanisme kuarter yang masih aktif. Segmen Sesar Siulak merupakan bagian dari sesar Sumatera, segmen ini berarah Baratlaut-Tenggara pergerakan dengan arah gaya kompresi Timurlaut-Baratdaya dan gaya ekstensional Baratlaut-Tenggara. Menurut Bellier and Sébrier (1994) Segmen Sesar Siulak merupakan bagian dari pergerakan Sesar Semangko yang bergerak menganan (dextral). Sedangkan menurut Sieh and Natawidjaja (2000), Sesar Siulak merupakan dilational step overs dan memanjang sekitar $\pm 70 \mathrm{~km}$, sesar inilah yang melintasi daerah penelitian. Pada Cekungan Sungai Penuh juga terdapat dua sistem sesar mayor yaitu Sesar Siulak Barat dan Sesar Siulak Timur dengan arah pergerakannya Dextral Fault.

\section{Stratigrafi Daerah Penelitian}

Berdasarkan korelasi satuan batuan pada daerah penelitian maka dapat diketahui jenis litologi batuan yang ada serta penyebaran batuan tersebut di daerah penelitian dalam bentuk formasi yang ada serta kedudukan batuan tersebut dimulai dari yang tertua sampai endapan batuan yang paling muda dimana proses-proses geologi berperan penting ini terlihat dari adanya batuan terobosan yang menerobos Formasi Hulusimpang yang dikatakan bahwa darah penelitian termasuk kedalam daerah vulkanik aktif.

\section{Dasar Teori}

Lereng adalah permukaan bumi yang membentuk sudut kemiringan tertentu dengan bidang horizontal. Lereng dapat terbentuk secara alamiah karena proses geologi atau karena dibuat oleh manusia. Menurut proses terbentuknya lereng terbagi menjadi 2 yaitu lereng alami dan lereng buatan.

Gerakan tanah adalah perpindahan massa tanah atau batu pada arah tegak, mendatar atau miring dari kedudukan semula, gerakan tanah mencakup gerak rayapan dan aliran maupun longsoran. Dari definisi gerakan tanah dapat disimpulkan bahwa longsoran adalah bagian dari gerakan tanah. Bergeraknya material tanah/ batuan dalam bentuk padat atau semi-viscous disebut sebagai pergerakan massa. Pergerakan massa ini dianalogikan dengan bergeraknya suatu blok pada bidang miring. Apabila gaya akibat gravitasi (beban bergerak) melebihi kuat geser penahan lereng, maka material akan bergerak (Basofi et al., 2016).

Kejadian bahaya longsor (gerakan massa tanah) sering terjadi di daerah lereng curam/ terjal. Terbentuknya longsor adalah akibat perpindahan material pembentuk lereng seperti batuan, bahan rombakan, tanah yang bergerak dari lereng bagian atas meluncur ke bawah. Secara prinsip longsor terjadi jika gaya pendorong pada lereng bagian atas lebih besar dari pada gaya penahan. Gaya pendorong dipengaruhi oleh 
intensitas hujan yang tinggi, keterjalan lereng, beban, ketebalan solum tanah, dan berat jenis tanah (Titisari et al., 2019).

Analisa kestabilan lereng bertujuan untuk menentukan faktor keamanan dari bidang longsor yang berpotensial. Analisis kestabilan lereng sering dijumpai pada perancangan bangunan seperti jalan raya, rel kereta api, tempat pemukiman penduduk, saluran air dan bendungan. Analisis kestabilan lereng ini dilakukan untuk mengecek keamanan dari lereng alam, lereng galian (Hardiyatmo, 1994).

Zona berpotensi longsor adalah daerah/ kawasan yang rawan terhadap bencana longsor dengan kondisi terrain dan kondisi geologi yang sangat peka terhadap bencana longsor luar, baik yang bersifat alami maupun aktifitas manusia sebagai faktor pemicu gerakan tanah, sehingga berpotensi terjadinya longsor.

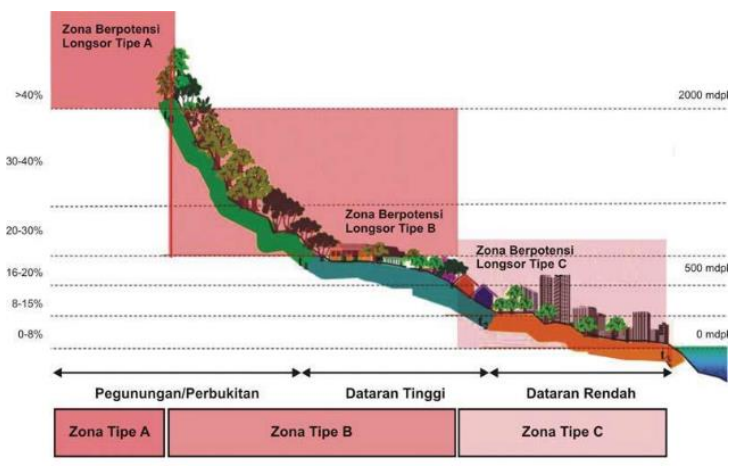

Gambar 2. Tipologi Zona Berpotensi Longsor (Departemen Pekerjaan Umum, 2005).

Sedangkan untuk menetapkan tingkat kerawanan zona tersebut dalam aspek fisik alami, digunakan kriteria sebagai berikut (Gambar 2):

1. Tingkat kerawanan Zona Berpotensi longsor tinggi apabila total nilai bobot tertimbang berada pada kisaran 2,403,00 .

2. Tingkat kerawanan Zona Berpotensi longsor sedang bila total nilai bobot tertimbang berada pada kisaran 1,702,39.

3. Tingkat kerawanan Zona Berpotensi Longsor rendah apabila total nilai bobot tertimbang berada pada kisaran 1,00-1,69.

\section{Metode Penelitian}

Penelitian ini berlokasi secara administratif berada di Desa Seberang, Kecamatan Pesisir Bukit, Kota Sungai Penuh, Provinsi Jambi. Metode penelitian yang digunakan berdasarkan pada parameter fisik, mekanik dan informasi yang berhubungan dengan penelitian dilakukan dengan cara metode pengamatan/ pemetaan lapangan, analisis laboratorium dan analisis studio. Metode survei yang dilakukan berupa survei pemetaan geologi permukaan yang dilakukan melalui observasi lapangan. Observasi di lapangan yang dilakukan meliputi orientasi medan, pengamatan morfologi, pengamatan singkapan dan batuan, pengukuran struktur geologi dan geometri lereng, pengambilan sampel batuan dan pengambilan sampel tanah. Pemetaan geologi dilakukan dengan melewati jalan, sungai dan tebing atau lereng perbukitan, bekas paritan dan titik ketinggian untuk mengamati bentuk bentangalam, struktur dan batuan yang ada di lapangan. Tahap penelitian dibagi menjadi tiga (3) sub tahapan yaitu:

1. Pengamatan geomorfologi, tahap ini dilakukan dengan mengamati daerah penelitian dan juga dilakukan penggambaran sketsa lapangan serta dokumentasi dengan menggunakan kamera agar mempermudah dalam penentuan bentukan lahan daerah penelitian lebih lanjut.

2. Pengamatan geologi meliputi deskripsi litologi, yaitu pengamatan terhadap sifat fisik batuan secara megaskopis dan pengambilan sampel batuan. Pengamatan sampel batuan secara megaskopis dilakukan dengan bantuan lup guna melihat kandungan mineral penyusun batuan dan komperator (beku dan sedimen) guna mengetahui jenis mineral penyusun batuan beku ataupun ukuran besar butir pada batuan sedimen, sehingga mempermudah dalam 
penentuan nama batuan saat di lapangan.

3. Pengukuran struktur geologi meliputi pengukuran unsur struktur dan kemiringan, struktur bidang serta arah dan penunjaman unsur struktur garis yang dimungkinkan sebagai pengontrol distribusi penyebaran batuan yang ada. Pengukuran struktur geologi dilakukan dengan bantuan kompas untuk mengukur parameter pada struktur geologi yang ditemukan, dan clipboard sebagai alat bantu saat mengukur.

Sebelumnya perlu dilakukan analisis data sekunder yang didapatkan dari pustaka dan sumber yang lain yang dapat digunakan sebagai bahan pertimbangan sebelum melakukan observasi lapangan detail, selanjutnya akan dibantu dengan pekerjaan laboratorium dan studio. Metode penelitian memuat lokasi penelitian, alat dan bahan yang digunakan, sumber data penelitian, teknik pengumpulan data, teknik pengolahan data, dan teknik analisis data.

\section{Alat dan bahan}

1. Kompas geologi, digunakan untuk mengetahui arah mata angin, mengukur slope, mengukur struktur geologi dan juga dapat dijadikan sebagai skala pembanding.

2. Kamera, digunakan untuk mengumpulkan foto sebagai data pendukung di lapangan.

3. Palu geologi, digunakan untuk pengambilan sampel dan juga dapat digunakan sebagai skala pembanding.

4. Komperator (beku dan sedimen), digunakan untuk mengetahui besar butir sampel yang didapat di lapangan dan penentuan nama batuan dilapangan.

5. Lup, digunakan untuk mengetahui komposisi batuan secara megaskopis.

6. GPS, digunakan untuk mengetahui koordinat dari setiap singkapan yang ditemui di lapangan lokasi pengambilan sampel untuk analisis stabilitas lereng.

7. Meteran, digunakan sebagai alat bantu ukur dalam pengukuran profil, MS ataupun pengukuran geometri lereng.
8. Borehand, digunakan untuk pengambilan sampel tanah jika dengan menggunakan pipa PVC sampel tidak dapat diambil.

\section{Hasil dan Pembahasan}

\section{Geologi Daerah Seberang dan Sumur Gedang}

Kondisi geomorfologi daerah penelitian tidak terlepas dari kondisi bentuk lahan, genesa dan juga proses geomorfologi yang terjadi. Penentuan geomorfologi dilakukan melalui pendekatan mengenai aspek geomorfologi. Berdasarkan analisis geomorfologi pada lokasi penelitian secara detail ditentukan berdasarkan interpretasi terhadap peta topografi, peta lintasan dan data citra satelit berupa data DEM, maka dasar pemisah dan penamaan satuan geomorfologi daerah penelitian mengacu pada Klasifikasi Verstappen (1985) dengan modifikasi (Tabel 1).

Pada daerah penelitian yang mengacu kepada klasifikasi bentuk lahan menurut Verstappen (1985) yaitu bentuk lahan perbukitan struktural (S1) dan bentuk lahan fluvial yang terdiri dari dataran fluvial (F1) dan tubuh sungai (F2) (Gambar 3). Satuan bentuk lahan ini kemudian disajikan kedalam peta geomorfologi daerah penelitian.

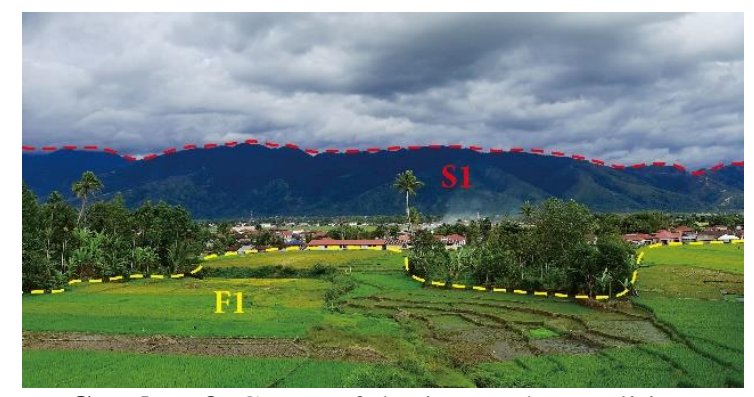

Gambar 3. Geomorfologi Daerah Penelitian.

Berdasarkan ciri litologi hasil observasi lapangan dan hasil analisis laboratorium, stratigrafi daerah penelitian 4 (empat) satuan batuan. Urutan satuannya dari tua ke muda adalah Intrusi Granit Sungai Penuh, Lava Basal Kebongsong, Breksi Vulkanik Kebongsong dan Endapan Aluvial. 
Tabel 1. Klasifikasi Geomorfologi Daerah Seberang dan Sumur Gedang (Berdasarkan

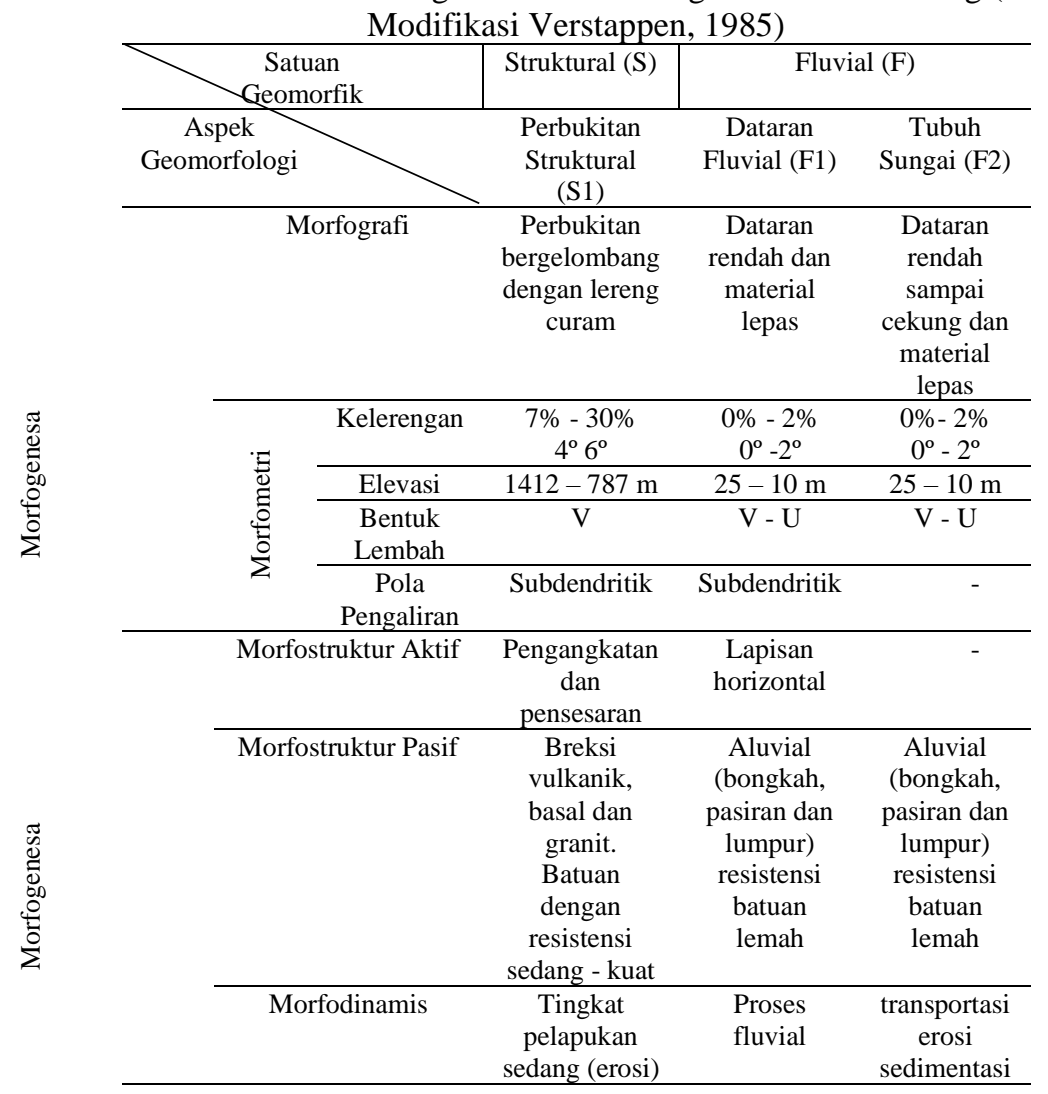

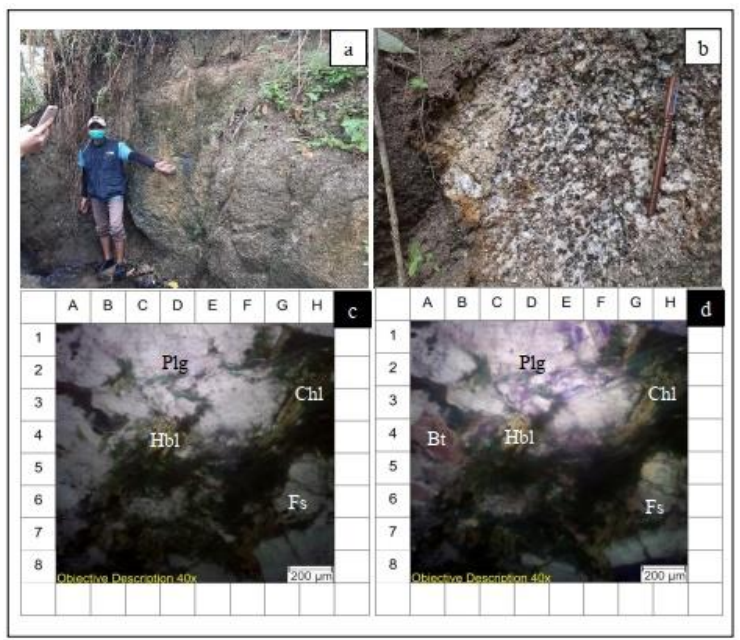

Gambar 4. a). Singkapan Granit, b). Sampel Granit, c). Sayatan Petrografi Granit PPL, d). Sayatan Petrografi Granit XPL

Intrusi Granit Sungai Penuh ini dicirikan dengan litologi batuan granit yang telah mengalami proses mineralisasi dan hampir keseluruhan singkapan telah mengalami pelapukan dan erosi terutama di daerah sungai bagian tebing di daerah penelitian. Intrusi Granit Sungai Penuh ini berumur Tersier-Pliosen. Batuan granit (Gambar 4) ini mencangkup $60 \%$ dari area penelitian. Batuan granit secara ciri-ciri megaskopis penyusun batuannya berwarna putih dengan bintik-bintik hitam, struktur masif, derajat kristalisasi holokristalin dan granularitas fanerik, susunan butiran ekwigranular (hampir seragam).

Satuan batuan ini berada pada bentang alam vulkanik dengan bentuk lahan berupa lereng atas vulkanik, karena material batuan yang ditemukan berupa material gunungapi yaitu lava. Batuan ini biasanya ditemukan pada fasies proximal (lereng atas vulkanik). Satuan Lava Basal Kebongsong ini terendapkan pada umur tersier awal. Satuan ini menepati $10 \%$ dari daerah penelitian. Batuan basal (Gambar 5) penyusun satuan ini memiliki ciri megaskopis memiliki warna segar hitam dan warna lapuk kelabu, struktur masif, tekstur porfiritik, derajat kristalisasi hipokristalin dan granularitas afanitik. 


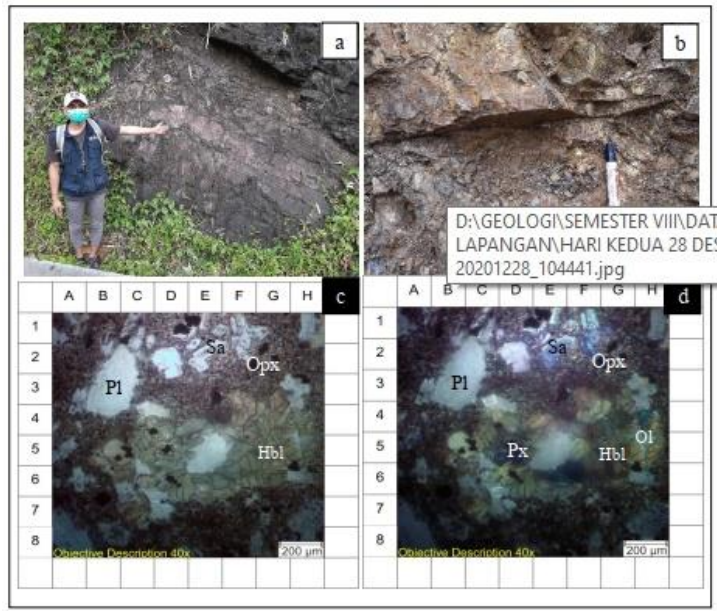

Gambar 5. a). Singkapan Basal, b). Sampel Basal, c). Sayatan Petrografi Basal PPL, d). Sayatan Petrografi Basal XPL

Breksi yang ditemukan memiliki ciri-ciri megaskopis dengan warna segar abu-abu hingga abu-abu kehitaman warna lapuk cokelat, struktur masif dan matriks berupa tuff. Berdasarkan material batuan gunungapi yang dihasilkan yaitu breksi vulkanik, maka satuan ini berada pada bentang alam vulkanik dengan bentuk lahan berupa lereng vulkanik atas. Satuan ini tersingkap di dinding tebing sepanjang jalan Kerinci-Ketapan. Satuan Breksi Vulkanik ini merupakan satuan batuan yang termasuk kedalam Formasi Qvkb (Batuan Gunungapi Andesit-Basalan Kebongsong) berdasarkan peta geologi regional, sehingga satuan ini berumur kuarter.

Fragmen breksi pada Gambar 6 secara megaskopis memiliki warna segar hitam dan warna lapuk kelabu, struktur masif, tekstur porfiritik, derajat kristalisasi hipokristalin dan granularitas afanitik.

Fragmen breksi pada Gambar 7 secara megaskopis memiliki warna segar abu-abu terang dan warna lapuk abu-abu muda, struktur masif, tekstur porfiritik, derajat kristalisasi hipokristalin dan granularitas afanitik, sedangkan pada nikol silang berwarna biru-orange, struktur masif, derajat kristalisasi hipokristalin, granularitas afanitik, bentuk mineral subhedraleuhedral, relasi inequigranular porfiritik.

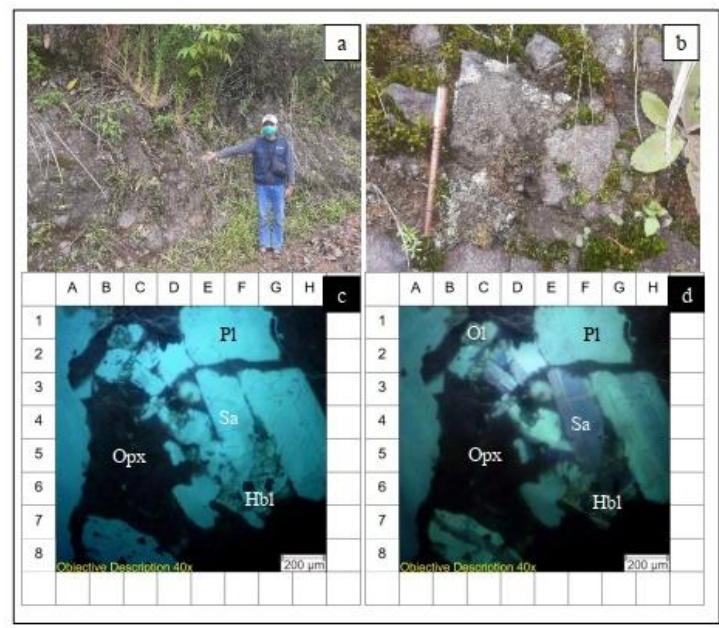

Gambar 6. a). Singkapan Breksi, b). Sampel Basal, c). Sayatan Petrografi Basal PPL, d). Sayatan Petrografi Basalt XPL

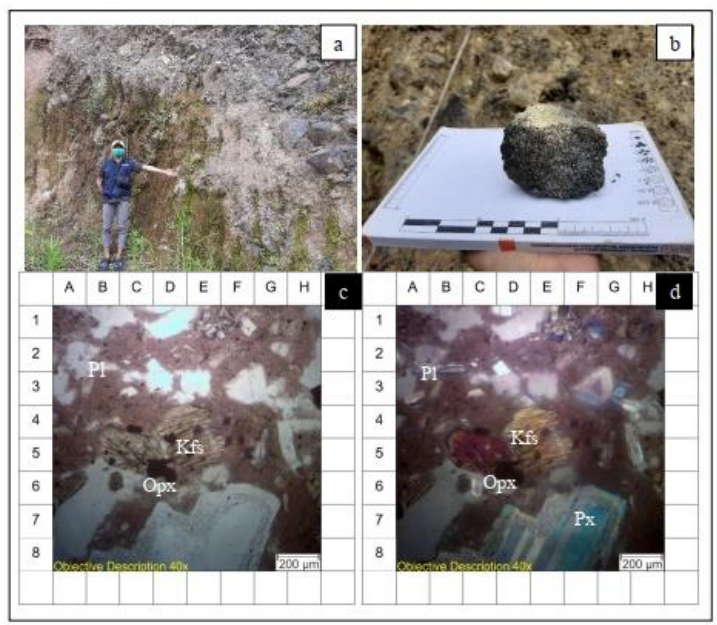

Gambar 7. a). Singkapan Breksi, b). Sampel Andesit, c). Sayatan Petrografi Andesit PPL, d). Sayatan Petrografi Andesit XPL

Endapan Aluvial (Gambar 8) termasuk kedalam satuan batuan kuarter aluvium. Endapan ini terdiri dari material lepas bongkah, kerikil, pasir, lanau dan lempung. Struktur batu berupa struktur batuan uncosolidated rock. Endapan aluvial ini banyak dimanfaatkan untuk tempat persawahan bagi masyarakat setempat. Endapan aluvial ini menutupi sekitar 35\% daerah penelitian. 


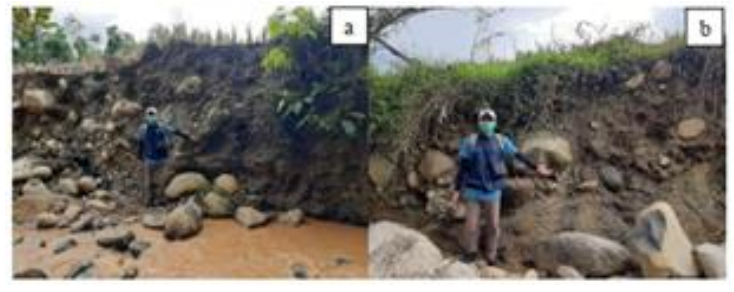

Gambar 8. a). Singkapan aluvial yang ada di dinding sungai b). Endapan Aluvial

(Dokumentasi Fandi Frananda dengan Azimuth N $\left.185^{\circ} \mathrm{E}\right)$

Tabel 2. Data Tabulasi Diagram Roset.

\begin{tabular}{cccccc}
\hline No & 1. & 2. & 3. & 4. & 5. \\
\hline \multirow{6}{*}{ Data } & $315 / 31$ & $43 / 12$ & $270 / 5$ & $145 / 35$ & $6 / 21$ \\
& $225 / 16$ & $260 / 23$ & $35 / 8$ & $142 / 35$ & $355 / 10$ \\
& $78 / 23$ & $98 / 17$ & $277 / 18$ & $323 / 40$ & $60 / 15$ \\
& $185 / 20$ & $115 / 21$ & $132 / 32$ & $110 / 21$ & $327 / 24$ \\
& $80 / 23$ & $320 / 97$ & $45 / 12$ & $322 / 35$ & $300 / 31$ \\
& $145 / 24$ & $92 / 17$ & $133 / 31$ & $15 / 20$ & $150 / 10$ \\
& $20 / 4$ & $329 / 24$ & $30-$ Oct & $147 / 35$ & $140 / 35$ \\
& $12 / 4$ & $355 / 11$ & $280 / 22$ & $309 / 33$ & $160 / 24$ \\
\hline
\end{tabular}

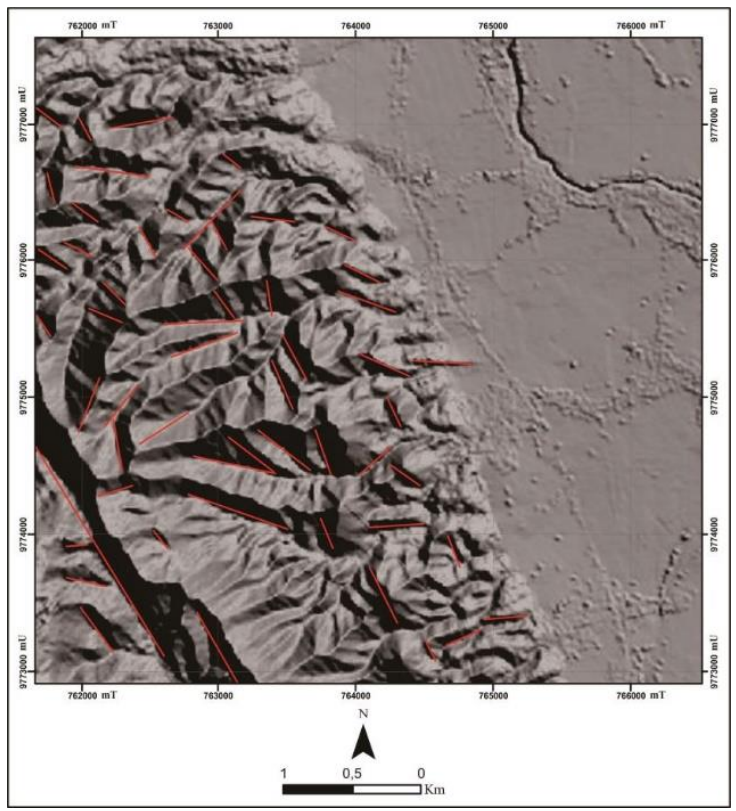

Gambar 9. Peta Kelurusan DEM Daerah Penelitian.

Pada daerah penelitian, data struktur geologi tidak ditemukan dikarenakan faktor singkapan yang ada di lapangan telah mengalami erosi serta pelapukan yang cukup berpengaruh terhadap struktur yang ada, dengan tidak adanya data primer struktur geologi yang ada di lapangan maka digunakan data sekunder (Tabel 2) yang didapatkan data Model Elevasi Digital (DEM) yaitu penarikan data kelurusan dengan menarik garis pada daerah-daerah lembah dari punggungan perbukitan untuk mengetahui arah dominan suatu kelurusan (Gambar 9 dan 10).

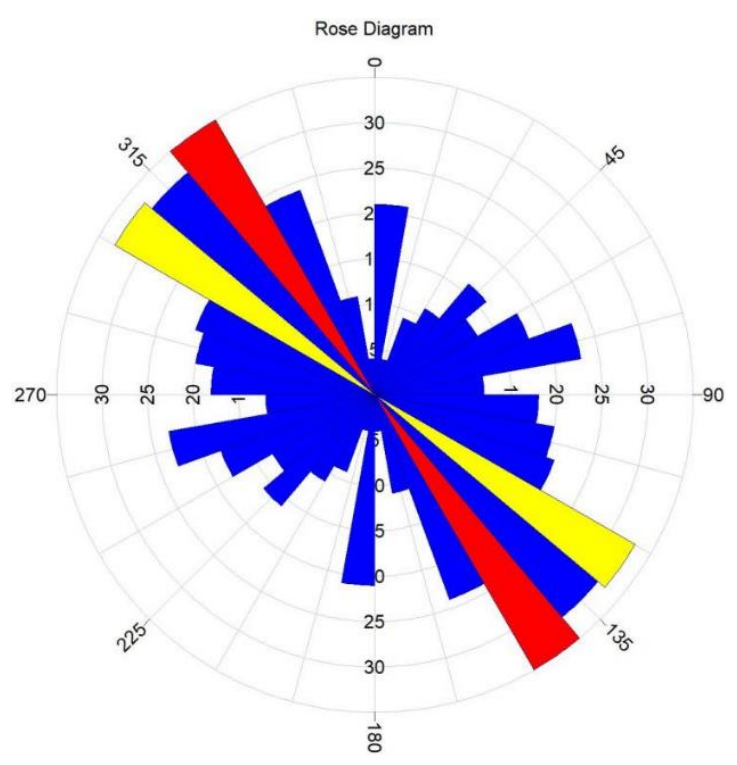

Gambar 10. Diagram Roset.

\section{Analisa Stabilitas Lereng}

1. Sifat Fisik Tanah

a. Kadar air

Tingginya nilai kadar air dapat mengindikasikan rongga butir atau porositas batuan atau tanah banyak terisi air sehingga mengurangi daya dukung tanah pada lokasi tersebut. Tabel 3 merupakan hasil uji kadar air sampel tanah.

Tabel 3. Hasil Uji Kadar Air.

\begin{tabular}{llll}
\hline Jenis Sampel & Kode Sampel & \multicolumn{2}{l}{ Kadar } \\
\hline \multirow{3}{*}{ Tanah } & Titik 1 & 39,247 & $\%$ \\
& Titik 2 & 36,387 & $\%$ \\
& Titik 3 & 45,121 & $\%$ \\
& Titik 4 & 52,803 & $\%$ \\
\hline
\end{tabular}

b. Berat Jenis Tanah

Penentuan faktor keamanan lereng menggunakan berat jenis. Semakin besar berat jenis suatu sampel tanah, maka akan semakin besar juga nilai faktor keamanannya. Tabel 4 adalah hasil uji berat jenis tanah. 
Tabel 4. Hasil Uji Berat Jenis Tanah

\begin{tabular}{lll}
\hline Jenis Sampel & Kode Sampel & Berat Jenis Tanah \\
\hline \multirow{3}{*}{ Tanah } & Titik 1 & 2,585 \\
& Titik 2 & 3,180 \\
& Titik 3 & 2,294 \\
& Titik 4 & 2,374 \\
\hline
\end{tabular}

c. Uji Saringan Tanah

Uji saringan merupakan uji yang dilakukan untuk menentukan pembagian butir tanah atau untuk menentukan persentase berat butiran tanah yang lolos dari satu set saringan. Tabel 5 menampilkan hasil uji saringan.

Tabel 5. Hasil Uji Saringan.

\begin{tabular}{llrr}
\hline Jenis & Kode & Persentase & \multicolumn{2}{l}{ Persentase } \\
Sampel & Sampel & Tertahan & \multicolumn{2}{l}{ Lolos } \\
\hline \multirow{3}{*}{ Tanah } & Titik 1 & 21,6 & 78,4 \\
& Titik 2 & 12,87 & 87,12 \\
& Titik 3 & 71,34 & 28,66 \\
& Titik 4 & 69,26 & 30,73 \\
\hline
\end{tabular}

\section{d. Atterberg Limit}

Hasil uji saringan dan atterberg limit dapat digunakan untuk menentukan nama dari masing-masing sampel tanah yang didapat. Penamaan ini dapat dilakukan dengan menggunakan nilai-nilai yang didapat dari besarnya persentase lolosnya butiran tanah pada saat uji saringan, nilai batas cair, batas plastis dan indeks plastisitas tanah yang didapat, semua nilai tersebut dimasukan kedalam grafik pengklasifikasian tanah kemudian disamakan dengan tabel klasifikasi tanah dari USDA dengan hasil pada Tabel 6.

Tabel 6. Hasil Uji Atterberg Limit.

\begin{tabular}{lcccc}
\hline \multirow{2}{*}{$\begin{array}{l}\text { Jenis } \\
\text { Sampel }\end{array}$} & \multicolumn{4}{c}{ Tanah } \\
\cline { 2 - 5 } $\begin{array}{l}\text { Kode } \\
\text { Sampel }\end{array}$ & Titik 1 & Titik 2 & Titik 3 & Titik 4 \\
$\begin{array}{l}\text { Batas } \\
\text { Cair }\end{array}$ & 48,452 & 54,1985 & 31,9025 & 46,2115 \\
$\begin{array}{l}\text { Batas } \\
\text { Plastis }\end{array}$ & 32,595 & 29,504 & 10,335 & 30,84 \\
$\begin{array}{l}\text { Indeks } \\
\text { Plastis }\end{array}$ & 15,857 & 24,695 & 21,568 & 15,372 \\
$\begin{array}{l}\text { Jenis } \\
\text { tanah }\end{array}$ & $\begin{array}{l}\text { Lempung } \\
\text { Berlanau }\end{array}$ & Lempung & Lempung & $\begin{array}{l}\text { Lempung } \\
\text { Berlanau }\end{array}$ \\
\hline
\end{tabular}

\section{Sifat Mekanik Tanah}

Uji sifat mekanik yang dilakukan terhadap sampel tanah adalah uji kuat geser langsung. Uji kuat geser langsung ini dilakukan sebanyak 3 kali pada sampel tanah yang sama namun dengan pemberian beban yang berbeda yaitu beban $5 \mathrm{~kg}, 10 \mathrm{~kg}$ dan $20 \mathrm{~kg}$ untuk melihat seberapa besar dan cepat keruntuhan yang terjadi pada beban yang berbeda yang hasilnya dapat dilihat pada Tabel 7.

Tabel 7. hasil Uji Kuat Geser Langsung.

\begin{tabular}{llcc}
\hline $\begin{array}{l}\text { Jenis } \\
\text { Sampel }\end{array}$ & $\begin{array}{l}\text { Kode } \\
\text { Sampel }\end{array}$ & $\begin{array}{l}\text { Sudut } \\
\text { Geser } \\
\text { Dalam }\left(^{(}\right)\end{array}$ & $\begin{array}{l}\text { Kohesi } \\
\left(\mathrm{Kg} / \mathrm{cm}^{2}\right)\end{array}$ \\
\hline \multirow{3}{*}{ Tanah } & Titik 1 & 44,953 & 0,0794 \\
& Titik 2 & 36,289 & 0,0669 \\
& Titik 3 & 22,898 & 0,1523 \\
& Titik 4 & 17,128 & 0,0822 \\
\hline
\end{tabular}

\section{Analisa Stabilitas Lereng}

Analisa stabilitas lereng dilakukan dengan menggunakan bantuan aplikasi slide 6.0, analisa lereng yang dilakukan pada daerah penelitian terdiri dari 4 lereng dengan material penyusun berupa tanah.

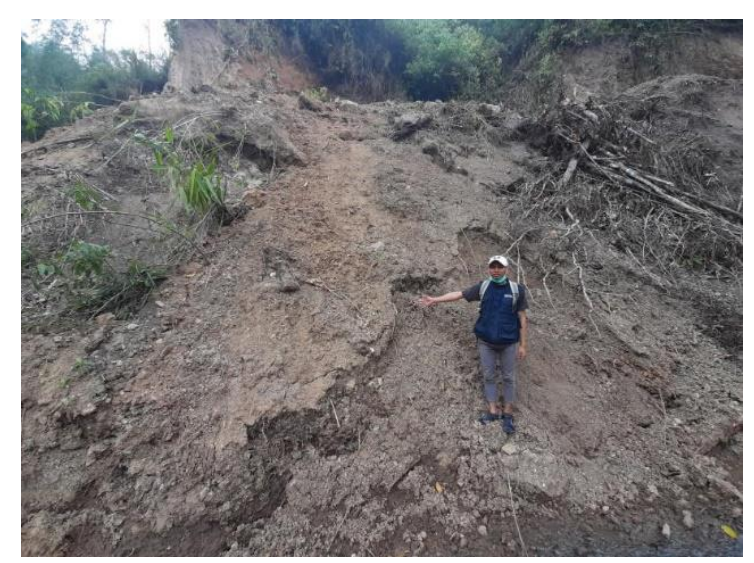

Gambar 11. Kenampakan Lereng Titik 1 di Lapangan.

Pada titik lokasi yang pertama yaitu Titik 1 (Gambar 11), memiliki dimensi lereng berupa kemiringan lereng dengan nilai $42^{\circ}$, tinggi lereng $10,6 \mathrm{~m}$, panjang lereng $8,4 \mathrm{~m}$, dan lebar lereng $6,35 \mathrm{~m}$. 
Berdasarkan data hasil analisis slide, faktor keamanan untuk titik 1 yang didapatkan adalah 1,443. Hasil analisis yang didapatkan > 1,25 (Gambar 12), sehingga lereng pada lokasi pengamatan ini termasuk lereng yang stabil-labil yang artinya sering terjadi gerakan tanah.

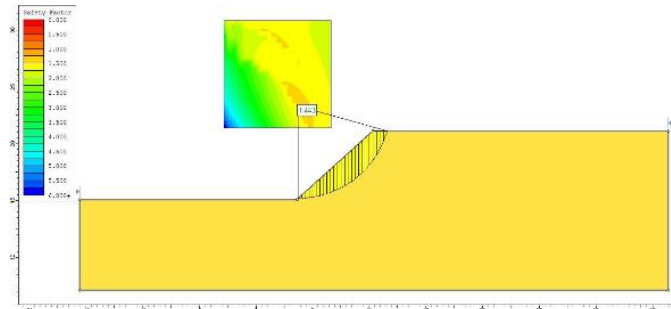

Gambar 12. Nilai FK Metode Bishop Lereng Titik 1 .

Pada titik lokasi yang kedua yaitu titik 2 (Gambar 13), memiliki dimensi lereng berupa kemiringan lereng dengan nilai $45^{\circ}$, tinggi lereng $15 \mathrm{~m}$, panjang lereng $19,5 \mathrm{~m}$, dan lebar lereng 15,6 m.

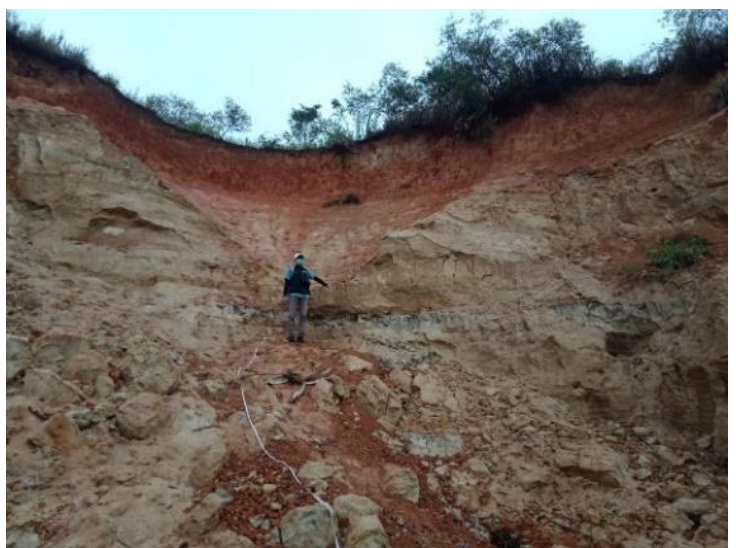

Gambar 13. Kenampakan Lereng Titik 2 di Lapangan.

Berdasarkan data hasil analisis slide, faktor keamanan untuk titik 2 yang didapatkan adalah 1,194 (Gambar 14). Hasil analisis yang didapatkan 80 memiliki nilai yang berada pada rentang $1,07-1,25$, sehingga lereng pada lokasi pengamatan ini termasuk lereng yang kritis, artinya pada lereng ini pernah terjadinya longsor, namun tidak terlalu sering jika dibandingkan pada lereng yang labil.

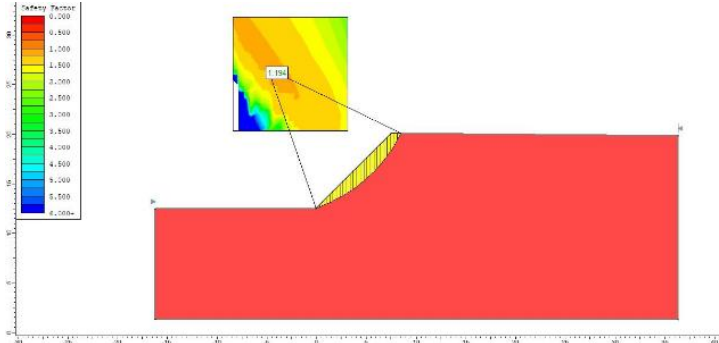

Gambar 14. Nilai FK Metode Bishop Lereng Titik 2.

Pada titik lokasi yang ketiga yaitu Titik 3 (Gambar 15), memiliki dimensi lereng berupa kemiringan lereng dengan nilai $66^{\circ}$, tinggi lereng $18 \mathrm{~m}$, panjang lereng $20,75 \mathrm{~m}$, dan lebar lereng $26,30 \mathrm{~m}$.

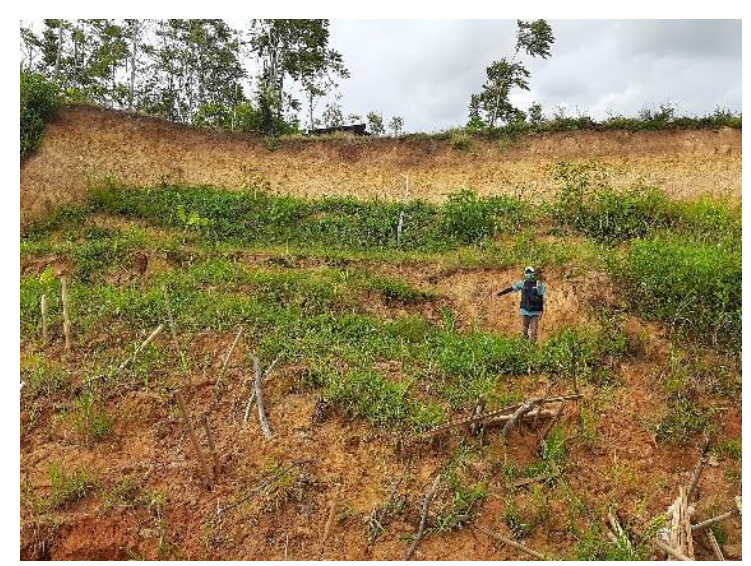

Gambar 15. Kenampakan Lereng Titik 3 di Lapangan.

Berdasarkan data hasil analisis slide, faktor keamanan untuk Titik 3 yang didapatkan adalah 0,525. Hasil analisis yang didapatkan memiliki nilai < 1,07 (Gambar 16), sehingga lereng pada lokasi pengamatan ini termasuk lereng yang labil.
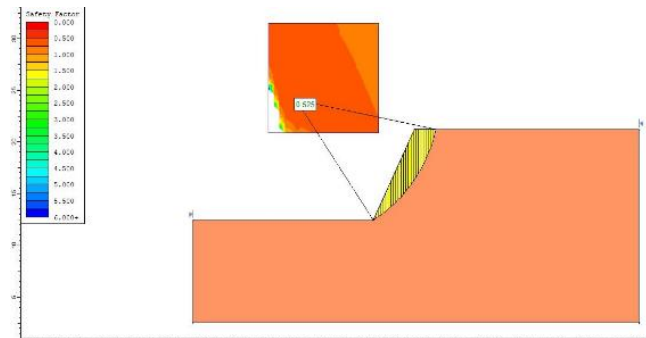

Gambar 16. Nilai FK Metode Bishop Lereng Titik 3

Pada titik lokasi yang keempat yaitu Titik 4 (Gambar 17), memiliki dimensi lereng berupa kemiringan lereng dengan nilai $58^{\circ}$, 
tinggi lereng $8 \mathrm{~m}$, panjang lereng $9,3 \mathrm{~m}$, dan lebar lereng $9,57 \mathrm{~m}$.

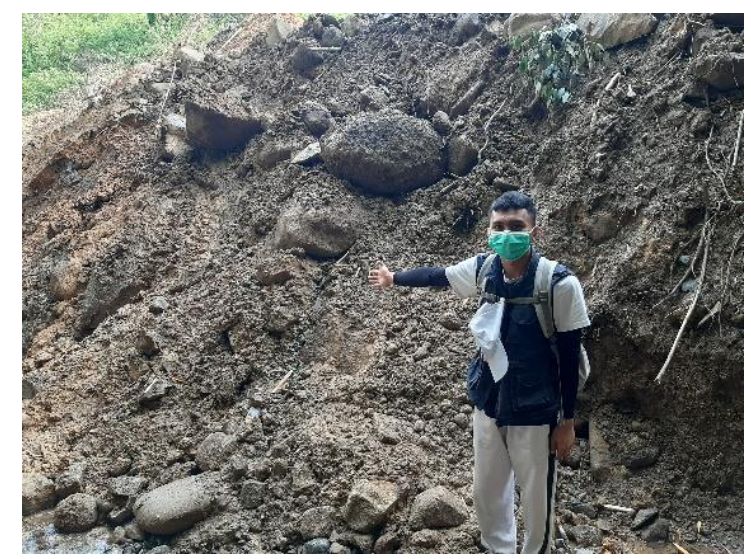

Gambar 17. Kenampakan Lereng Titik 4 di Lapangan

Berdasarkan data hasil analisis slide, faktor keamanan untuk titik 4 yang didapatkan adalah 0,65 (Gambar 18). Hasil analisis yang didapatkan memiliki nilai < 1,07, sehingga lereng pada lokasi pengamatan ini termasuk lereng yang labil.

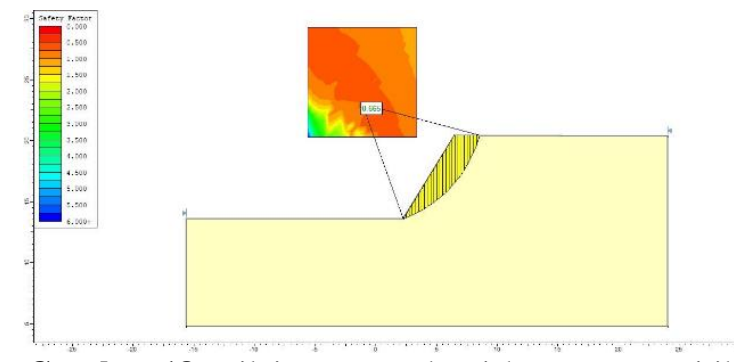

Gambar 18. Nilai FK Metode Bishop Lereng Titik 4

\section{Zonasi Kerentanan Longsor}

Penentuan zona kerentanan longsor berdasarkan parameter besarnya kemiringan lereng, curah hujan dan tata guna lahan serta sebaran batuan pada daerah penelitian. Peta yang telah dibuat seperti peta kemiringan lereng, peta penggunaan lahan, peta geologi, peta geomorfologi di-overlay sehingga akan didapatkan peta zonasi longsor dengan kategorinya masing-masing. Klasifikasi zona kerentanan longsor terbagi menjadi tiga, yaitu zona kerentanan longsor rawan, cukup rawan dan tidak rawan. Berdasarkan hasil analisis data yang didapatkan, zonasi rawan bencana longsor pada daerah penelitian terbagi menjadi 5 yaitu tidak rawan, agak rawan, cukup rawan, agak rawan dan tidak rawan.

Berdasarkan zonasi longsor pada daerah penelitian di atas dapat dilihat pada peta zonasi longsor (Gambar 19), daerah penelitian terbagi dalam 2 zona yaitu zona potensi longsor rendah (stabil) hingga zona potensi longsor tinggi (labil). Zona berpotensi tanah longsor rendah menandakan bahwa pada daerah tersebut dapat ditemukan adanya tanah longsor, namun ditemukannya tanah longsor ini jarang, tanah longsor dapat terjadi pada daerah ini jika adanya faktor yang memicu longsor. Zona berpotensi tanah longsor menengah menandakan bahwa pada daerah tersebut ditemukannya kejadian longsor cukup banyak, umumnya ditemukan pada daerah yang berbukit dengan curah hujan yang cukup tinggi serta tutupan lahan yang memicu terjadinya longsor. Sedangkan zona berpotensi longsor tinggi menandakan bahwa pada daerah tersebut sangat berpotensi menimbulkan bencana longsor, umumnya ditemukan pada daerah dengan lereng yang agak terjal hingga terjal dengan intensitas curah hujan yang tinggi dan bencana tanah longsor pada daerah ini akan sering terjadi. 


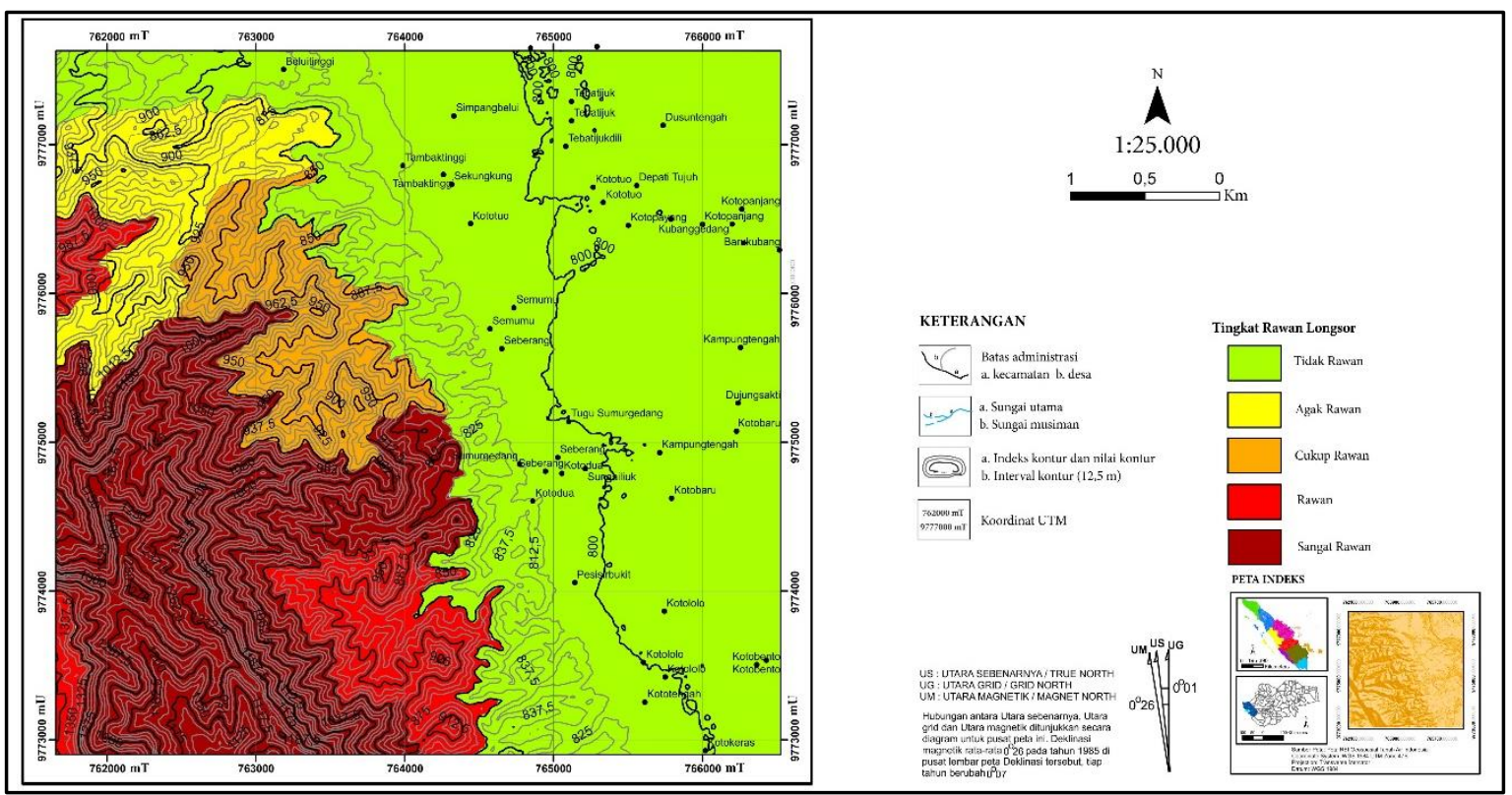

Gambar 19. Peta Zonasi Longsor Desa Seberang dan Sumur Gedang.

\section{Kesimpulan}

Berdasarkan tujuan penelitian ini, maka dapat disimpulkan bahwa Pertama, batuan breksi dengan sifat kompaksi antar fragmennya yang kecil dapat menyebabkan tingkat kerentanan longsornya sangat tinggi dengan kemiringan lereng curam. Batuan granit yang ditemukan kebanyakan telah megalami proses erosi cukup tinggi juga sangat berpengaruh terhadap kestabilan lereng.

Kedua, penentuan zonasi longsor didapatkan dari overlay peta geologi, geomorfologi, penggunaan lahan, kelerengan dan data curah hujan dan beberapa analisis yang dilakukan terhadap sampel tanah baik secara fisik maupun mekanika. Terdapat 5 tingkatan kerawanan longsor yaitu sangat rawan, rawan, cukup rawan, agak rawan dan tidak rawan. Ketiga, upaya penanggulangan dan pengendalian di daerah penelitian, antara lain melalui rekayasa keteknikan, mengubah geometri lereng yaitu dengan melandaikan lereng yang curam, membuat parit permukaan yaitu diletakkan di bagian atas lereng pada agian tanah lereng yang stabil, membuat dinding penahan dari batuan yaitu sebagai peyangga di bawah kaki lereng, pengendalian Pemanfaatan Ruang
Kawasan Rawan Bencana Gerakan Tanah/ Longsor, dan melakukan perlindungan sistem hidrologi kawasan.

\section{Daftar Pustaka}

Basofi, A., Fariza, A., and Dzulkarnain, M. 2016. Landslides susceptibility mapping using fuzzy logic: A case study in Ponorogo, East Java, Indonesia. 2016 International Conference on Data and Software Engineering (ICoDSE), 1-7. https://doi.org/10.1109/ICODSE.201 6.7936156

Bellier, O., and Sébrier, M. 1994. Relationship between tectonism and volcanism along the Great Sumatran Fault Zone deduced by spot image analyses. Tectonophysics, 233(3), 215-231.

https://doi.org/https://doi.org/10.1016 /0040-1951(94)90242-9

Bemmelen, R.V. 1949. The Geology of Indonesia Vol 1A: General Geology of Indonesia and Adjacent Archipelagoes. Goverment Printing, The Hague.

Das, B.M., Endah, N., and Mochtar, I.B. 1995. Mekanika Tanah (Prinsip Prinsip Rekayasa Geoteknis) (1st ed.). Erlangga. 
Departemen Pekerjaan Umum. (2005). Pedoman Teknis Departemen Pekerjaan Umum Pd T-09-2005-B tentang Rekayasa Penanganan Keruntuhan Lereng Pada Tanah Residual dan Batuan.

Dinas Pekerjaan Umum. (2015). Data Pembangunan Sistem Penyedia Prasarana Air Minum 2005-2007. Kabupaten Belitung Timur.

Hardiyatmo, H.C. 1994. Mekanika Tanah 2 (1st ed.). Gramedia Pustaka Utama.

Natawidjaja, D.H. 2018. Updating active fault maps and sliprates along the Sumatran Fault Zone, Indonesia. IOP Conference Series: Earth and Environmental Science, 118(1), 1-11. https://doi.org/10.1088/17551315/118/1/012001

Sieh, K., and Natawidjaja, D.H. 2000. Neotectonics of the Sumatran fault, Indonesia. Journal of Geophysical Research: Solid Earth, 105(B12), 28295-28326. https://doi.org/10.1029 /2000JB900120

Titisari, A.D., Husna, H.Z.K., Putra, I.D., and Indrawan, I.G.B. 2019. Penentuan Zona Kerentanan Longsor Berdasarkan Karakteristik Geologi dan Alterasi Batuan. Jurnal Pengabdian Kepada Masyarakat (Indonesian Journal of Community Engagement), 4(2), 141-158. https://doi.org/10.22146/jpkm.35935

Verstappen, H.T. (1985). Applied Geomorphological Survey and Natural Hazard Zoning. ITC syllabus. The Netherlands. 